\title{
Article
}

\section{Match injuries in professional soccer: inter-seasonal variation and effects of competition type, match congestion and positional role}

Carling, C., Orhant, E., and Le Gall, F.

Available at http://clok.uclan.ac.uk/12337/

Carling, C. ORCID: 0000-0002-7456-3493, Orhant, E., and Le Gall, F. (2010) Match injuries in professional soccer: inter-seasonal variation and effects of competition type, match congestion and positional role. International Journal of Sports Medicine, 31 (4). pp. 271-276. ISSN 0172-4622

It is advisable to refer to the publisher's version if you intend to cite from the work. http://dx.doi.org/10.1055/s-0029-1243646

For more information about UCLan's research in this area go to http://www.uclan.ac.uk/researchgroups/ and search for <name of research Group>.

For information about Research generally at UCLan please go to http://www.uclan.ac.uk/research/

All outputs in CLoK are protected by Intellectual Property Rights law, including Copyright law. Copyright, IPR and Moral Rights for the works on this site are retained by the individual authors and/or other copyright owners. Terms and conditions for use of this material are defined in the policies page. 
This is a pre-proof corrected manuscript, as accepted for publication, of an article

2 published by Thieme eJournals in International Journal of Sports Medicine on $17^{\text {th }}$

3 February 2010, available online:

4 https://www.thieme-connect.com/DOI/DOI?10.1055/s-0029-1241212

PLEASE REFER TO THE PUBLISHED VERSION FOR CITING PURPOSES

8 Match injuries in professional soccer: inter-seasonal variation and effects of competition type, match congestion and positional role

itutions:

${ }^{1}$ LOSC Lille Métropole Football Club, Domain de Luchin, Camphin-en-Pévèle, 59780, France;

${ }^{2}$ Olympique Lyonnais Football Club, 350 avenue Jean Jaurès, 39361, Lyon, Cedex 07, France.

Correspondance: Christopher Carling, EMSP, LOSC Lille Métropole Football Club, Domain de Luchin, Camphin-en-Pévèle, 59780, France.

Phone: 00.33.1.4891 0793

Fax: 00.33.1.4891 0793

Email: chris.carling@free.fr

26 Running head: Injury in professional soccer 
1 Abstract

2 In this prospective observational study, injuries sustained in official match-play in 3 players belonging to a professional soccer club were investigated. Incidence and 4 patterns of injury were compared across four-seasons (2005-2006: S1, 2006-2007: S2, 5 2007-2008: S3 and 2008-2009: S4) and 3 match formats (domestic League/Cup games 6 and European club competition). In addition, the effects of both fixture congestion and 7 the positional role of players were investigated. Injury incidence (per 1000 match-hours) 8 did not vary between seasons (range 31.2-59.2 observed in S2 and S4 respectively, $9 \mathrm{p}=0.12$ ) or fixture formats (range 32.6-40.8 observed in European and League matches 10 respectively, $\mathrm{p}=0.49)$. In contrast, rates varied in players $(\mathrm{n}=7)$ who participated in all 11 four seasons as more injuries were sustained in S1 compared to S2 and S3 respectively 12 (88.4 vs. 49.0 vs. 49.2 , both $\mathrm{p}<0.05)$. The incidence of muscle strains was higher in S4 13 versus S3 $(24.7$ vs. 9.9, $\mathrm{p}<0.05)$ as were injuries sustained to the ankle region in S4 14 versus S2 (15.1 vs. 4.5, $\mathrm{p}<0.05)$. The incidence of joint sprains differed between fixture 15 formats with a higher rate observed in League versus both Cup and European 16 competition respectively ( 10.1 vs. 3.0 vs. 3.0 , both $\mathrm{p}<0.05)$. Injury incidence was not 17 associated to the time delay (number of days) separating games $(r=0.04, p=0.58)$. A 18 very short interval ( $\leq 3$ days) between fixtures did not result in a greater injury rate $19(\mathrm{p}=0.40)$ or number of days lost to injury $(\mathrm{p}=0.73)$ compared to a longer interval 20 ( $\geq 4$ days). Finally, the incidence of injury and muscle strains (both $p<0.001$ ) varied

Keywords

Football; Injury incidence; Time-loss injury, Epidemiology, Severity 
Introduction

In professional soccer, the risk of injury is considerable and injury is the major single factor affecting player availability [24]. In general, there is a substantially higher risk of sustaining injury in match-play compared to in training. Research at elite levels has reported incidences of injury in match-play ranging from a minimum of 24.6 per 1000 hours exposure in an English professional soccer club [24] to a maximum of 88.7 per 1000 hours exposure in teams competing in FIFA organised and other international tournaments [20]. However, investigations have tended to examine match injuries across one or two seasons $[7,8,10,11,13,19,22,24,25]$ or during tournaments $[3,6,14,16,20]$. To our knowledge, data on match injury rates collected and compared over multiple seasons are scarce $[8,17]$. In addition, there is limited information on injury patterns and severity across seasons [8] and further research on inter-seasonal variations in injury is therefore warranted.

In contemporary European professional soccer, teams can participate in up to 70 competitive matches per season [7]. In addition to their League programmes, teams compete in domestic cup competitions and some will participate in European club competitions. It has been suggested that increased exposure time to match-play at the highest levels of European soccer is linked to a high risk of underperformance and injury [5,25]. However, there are no data on injury incidence in these specific forms of match-play and whether they affect overall injury rates across a playing season. This information may aid in determining the playing resources required with regard to injuries across the season especially when participating in additional competitions.

Similarly, fixture congestion is regarded as a threat to team performance and player health [21]. Yet, only limited data are available on the relationship between calendar congestion and injury rates [7]. At professional levels, the performance level of 
1 players in official competition is reduced when the time delay is short between

2 consecutive games [23]. As professional clubs are frequently subjected to playing

3 consecutive games within a tight time frame (e.g. $\leq 3$ days), an investigation examining

4 whether there is an increased risk of injury and whether the severity of injury is greater

5 after a short delay between matches is warranted.

6 Finally, a limited amount of studies have examined the effects of playing 7 position on the risk of sustaining injury [17,22] and to our knowledge, there is no 8 information on the individual patterns and severity of injuries in match-play. In

9 addition, studies simply differentiate injury between forward, midfield and defending 10 positional groups. Analysis of elite performance suggests that the demands of the game 11 are unique and are dependent upon the precise individual positional role of the player 12 (e.g., separation between central- and wide-midfielders or central-defenders and full13 backs) [4,5]. An investigation of injury rates and patterns in match-play according to the 14 precise individual positional role of the player is merited.

The aims of this prospective study of injury rates, patterns and severity in match-

16 play in a professional soccer club were three-fold: 1) to compare injury across four-

17 seasons and three official match formats; 2) to investigate the effects of match 18 congestion on injury; 3) to compare injury according to the individual positional role of 19 the player.

21 Material and Methods

22 In this prospective observational study, injuries sustained in players belonging to the

23 first-team squad of a French League-1 Club were diagnosed and documented by the 24 team's physician over four-seasons. Ethics approval was obtained from the internal 25 review board of the sampled football club. This study meets the ethical standards of the 
1 International Journal of Sports Medicine [15]. To ensure team and player

2 confidentiality, all performance data were anonymised before analysis. were categorised into one of six individual playing positions. These positions included: goalkeepers, full-backs, central-defenders, wide- and central-midfielders and centre-

6 forwards [4,5]. Epidemiological data were collected according to the position itself and 7 not the player who played in that role.

Data were captured during the entire 2005-2006, 2006-2007, 2007-2008 and

9 2008-2009 seasons respectively. In 2005-2006, the club participated in the UEFA

10 Champions League (CL) before entering the UEFA Cup (now the UEFA Europa

11 League). In 2006-2007, the club again participated in the CL and reached the first

12 knockout round after qualifying from the group stage. Exposure time to official 13 competition (Domestic League and Cup and European Competition) was recorded for 14 each individual player.

Only first-team match injuries were considered and inclusion criteria were those

16 injuries leading to a player being unable to fully participate in future training or matches

17 (i.e. time-loss injury). Injuries sustained in players when participating in training sessions or matches for their national team were not included for analysis. The type, location, and severity of the injury (layoff time) were recorded, the latter depending on

20 the number of days the player was absent from and unable to take full part in training or 21 competition. All injuries were followed until the final day of rehabilitation. The player 22 was considered injured until the team physician allowed full participation in collective 23 training and availability for match selection. Finally, the date of each injury was 24 recorded to examine inter-monthly variations in injury incidence across the playing 
1 season. Not examined in this study were the cause of injury and the time period in the

2 match when the injury was sustained.

3 The methodologies and definitions of injury used in the present study closely

4 follow those recommended by International Soccer Injury Consensus Groups $[9,12]$ and

5 are similar to those employed in other investigations on elite soccer play $6 \quad[3,6,10,11,14,18,19,24,25]$.

7 All statistical analyses were conducted using SPSS for Windows Version 14.0

8 (SPSS Inc., Chicago, IL, USA). Results are reported as means and standard deviations

9 (mean \pm SD) calculated by conventional procedures unless otherwise stated. The

10 statistical methods applied were frequencies, cross-tabulations and descriptive statistics.

11 Injury incidences are reported as injuries/1000 player match-hours (95\% confidence

12 interval) unless otherwise stated. A Kruskal-Wallis One-Way Analysis of Variance on

13 Ranks test was used to compare injury incidences in official competition between

14 seasons and across the three match formats: Domestic League and Cup and European

15 Competition. Follow-up univariate analyses using Tukey's HSD test were employed

16 where appropriate. A Repeated Measures Analysis of Variance on Ranks was used to

17 investigate injury rates in players who participated across all 4 seasons. The relationship

18 between the time delay (in days) separating games and injury incidence was explored

19 using Pearson's product-moment correlation. A Mann-Whitney $U$ test was used to test

20 injury incidence and layoff time after a short delay ( $\leq 3$ days) compared to a longer delay

21 ( $\geq 4$ days) between games. The significance level was set at $\mathrm{p}<0.05$.

23 Results 
1 Over the four-seasons, a total of 192 matches were played (Table 1) with a median of 23

2 matches per player per season (range: 1-48 matches). Players were exposed to a total of

$3 \quad 3246.7$ hours match-play (range across seasons: 709.8-912.1 hours).

4

$5 \quad$ Table 1 about here.

6

7 Injury patterns across seasons and competition formats

Across the four seasons, a total of 130 match injuries (40.0\%) were classed as

9 time-loss injuries. Incidence of injury according to playing season and match format are

10 presented in Table 1 . Injury incidence peaked in the 2008/09 season but did not vary

11 between seasons $(\mathrm{p}=0.120)$. In contrast, injury incidence varied significantly between

12 seasons in 7 players who participated in all four seasons $(\mathrm{p}=0.037)$ with a higher rate of

13 injury reported in 2005/06 (88.4) compared to in 2006/07 (49.0) and 2007/08 (49.2)

14 (both $\mathrm{p}<0.05$ ). While injury incidence was highest in League matches, no difference

15 was observed between competition formats $(\mathrm{p}=0.496)$.

16 Table 2 reports the nature and anatomic location of injuries across the four-

17 season study period. Traumatic and overuse injuries constituted $84.6 \%$ and $15.4 \%$ of the

18 total number of injuries respectively. Overall, muscle strains were the most common

19 type of injury sustained (33.9\%) followed by joint sprains (22.3\%) and

20 contusions/haematomas $(20.0 \%)$. Injuries to the knee region $(21.5 \%)$ were most

21 common followed by the ankle $(20.0 \%)$ and the lower leg $(10.0 \%)$ regions. Of the

22 strains, 58.8\% affected the upper leg and $11.0 \%$ the lower leg while sprains $(69.0 \%)$ and

23 contusions (34.6\%) mostly concerned the ankle and knee respectively.

24 Due to small numbers, the rates of only the most common injury types

25 (contusions, sprains and strains) and locations (ankle, knee, lower leg, hamstring and 
1 groin) were compared between seasons and match formats. Muscle strains varied across

2 seasons ( $\mathrm{p}=0.043$ ) with a higher incidence observed in 2008/09 versus 2007/08 (24.7 vs.

$39.9, \mathrm{p}<0.05)$. Similarly, there was a difference between seasons in the incidence of ankle

4 injuries $(\mathrm{p}=0.037)$ as more injuries to this region were sustained over the $2008 / 09$

5 season compared to the $2006 / 07$ season $(15.1$ vs. $4.5, \mathrm{p}<0.05)$. While the occurrence of

6 joint sprains varied according to match format $(\mathrm{p}=0.042)$ with a higher incidence

7 observed in League versus both Cup and European competition (10.1 vs. 3.0 vs. 3.0,

8 both $\mathrm{p}<0.05$ ), there was no difference between competition formats in the rate of injury

9 to any of the five anatomic locations.

11 Table 2 about here.

13 Overall, the mean layoff time per injury was $15 \pm 26$ days. While no significant

14 difference was reported between seasons for the mean layoff time per injury $(\mathrm{p}=0.242)$,

15 values varied substantially (range: $8 \pm 7$ days in 2006/07 to $24 \pm 20$ days per injury in

16 2007/08. Similarly, no difference between seasons in mean layoff time was reported in

177 players who participated in all four seasons $(\mathrm{p}=0.278)$. Again, while no difference was

18 observed in mean layoff time per injury between competition formats $(p=0.184)$, a

19 considerably longer layoff was observed in League Competition (15 \pm 29 days)

20 compared to Cup games ( $9 \pm 8$ days).

22 Inter-seasonal variations and effects of match congestion

The overall incidence of injury varied between months $(\mathrm{p}<0.001)$ and peaked in

24 March (59.6 per 1000 hours exposure) and was lowest in May (19.9 per 1000 hours

25 exposure) (Figure 1). 
Over the four year period, the mean recovery time between games was $5 \pm 3$

2 days. Altogether, 76 games were played with a short time interval ( $\leq 3$ days) and 116

3 games with a longer interval ( $\geq$ 4days) separating competition. No association was

4 observed between the time interval separating games and injury incidence $(r=0.038$,

$5 \mathrm{p}=0.581)$. Similarly, no difference $(\mathrm{p}=0.406)$ was observed in the incidence of injury

6 after a short interval separating games $(45.0 \pm 54.6$ per 1000 hours, $0.8 \pm 0.9$ injuries

7 per match) compared to that after a longer interval $(37.7 \pm 48.4$ per 1000 hours, injuries

$80.6 \pm 0.8$ per match). Altogether, 57 injuries ( $43.8 \%$ of the total) were sustained after a

9 short interval separating games of which $57.9 \%$ were sustained by a player who had

10 played in both games. In comparison, 73 injuries $(56.2 \%$ of the total) were sustained

11 after a longer interval of which $67.1 \%$ were incurred in a player who had played in both

12 games. Layoff time per injury was identical ( $15 \pm 25$ days vs. $15 \pm 28$ days, $\mathrm{p}=0.730)$

13 between consecutive games separated by a short versus a longer interval.

$15 \quad$ Figure 1 about here.

17 Positional differences

18 Table 3 reports the overall incidence of injury, mean layoff time per injury and

19 the most common types of injury sustained according to positional role. A difference in

20 the overall incidence of injury was observed between positional roles $(p<0.001)$ with

21 centre-forwards recording the highest rate (post hoc differences from $\mathrm{p}<0.05$ to $\mathrm{p}<0.001$

22 versus other positional roles). While the mean injury layoff duration did not vary

23 between positional roles $(\mathrm{p}=0.544)$, there was a difference in the incidence of muscle

24 strains $(\mathrm{p}<0.001)$ with the highest rate of these injuries reported in centre-forwards (post

25 hoc versus all positional roles, $\mathrm{p}<0.001)$. Muscle strains were the most common injury 
1 across all positional roles except in central-defenders in whom sprains were more

2 frequently observed. No differences were reported for any of the injury locations across 3 playing positions.

4

$5 \quad$ Table 3 about here.

6

7 Discussion

The aim of this four-season study on injury rates and patterns in a professional

9 soccer club was to examine inter-seasonal variations in match injuries and the effects of 10 match type, fixture congestion and positional role on injury. Results showed that 11 incidence and severity of match injury did not vary between seasons and were not 12 influenced by competition format. In contrast, the incidence of injury varied across 13 seasons in players who participated in all four seasons. The incidence of muscle strains 14 and injuries to the ankle regions differed across seasons as did the rate of joint sprains 15 between fixture formats. Injury rates were not associated to the time interval between 16 games and a very short interval between fixtures did not result in a higher injury risk or 17 layoff time. A higher overall risk of sustaining injury and muscle strains in particular was observed in centre-forwards compared to the other positional roles. In the present club, the overall incidence of match injury (40.5) was substantially

20 higher than rates previously reported for other professional soccer clubs in equivalent 21 European Leagues [8,18,24,25]. Regional differences in injury incidences and patterns 22 due to playing style or intensity and climate may explain this discrepancy [25]. 23 However, the stable injury incidence over the study period is in agreement with the 24 results of two recent studies in that injury rates in other professional European soccer 25 clubs were stable over a two- [13] and seven-season period respectively [8]. This 
1 finding is noteworthy and suggests that the risk of sustaining injury in players in the

2 present club whilst higher than that reported in other professional clubs, has not

3 changed over a four-season period. In contrast, the significant inter-seasonal variation in

4 injury rate observed in players who participated in all four seasons is noteworthy.

5 Similarly, the significant difference between seasons in muscle strains and injuries to

6 the ankle region for the entire squad is of interest and is in accordance with previous

7 research that patterns of injury can vary across seasons $[8,13]$. Hägglund and co-

8 workers [13] suggested that disparities in injury patterns may reflect natural variations

9 across seasons or differences in the study environment. Another possible explanation

10 for the present inter-seasonal variations may be changes in coaching staff and training

11 methods or player turnover. Indeed, the former has a major influence on injury

12 prevention especially in the design of training programmes and the safety culture it

13 promotes [26]. Nevertheless, these findings suggest the need for a prolonged injury

14 study period to ensure consistent, in-depth, and accurate injury profiles in elite soccer.

15 The findings also emphasise the permanent need for individualised monitoring of injury

16 rates and patterns as well as the implementation and evaluation of injury prevention

17 measures.

18 Participation in top European Competition did not result in a higher overall

19 injury rate across seasons as no differences in injury incidence were observed in these

20 matches compared to League games. In addition, the severity of injury did not vary

21 according to competition format. These results imply that participation in other forms of

22 competition did not influence the risk or seriousness of injury in the present elite

23 footballers and also suggests that the club coped well with the additional burden of

24 European competition and domestic Cup matches. However, the chance of sustaining a

25 joint sprain was dependent on fixture format with the highest rate observed in domestic 
1 League games. It is difficult to suggest valid reasons for this discrepancy and further

2 research is merited especially in regard to the causes of these injuries across the 3 different competition formats.

In this study and in general accordance with the medical literature, injury rates and patterns varied substantially over the course of the playing season with overall

6 injury incidence peaking in March. However, no association was observed between the

7 time delay separating games and injury rate. Similarly, when the team was forced to

8 play consecutive games separated by a short interval ( $\leq 3$ days), injury rate and layoff

9 time were comparable to those after a longer interval ( $\geq 4$ days). This result implies that

10 congested periods of match-play did not increase injury risk or severity. The club's

11 player rotation policies and/or recovery strategies may be a reasonable explanation for

12 this result. These findings lend support to findings in professional Spanish soccer in that

13 the results of teams in official competition are not affected by fixture congestion and

14 that players are quite capable of coping with a busy match schedule.[21] Findings from

15 this study may therefore assure coaches, support staff and players alike that in a 16 professional setting, high-performance soccer players can cope with a congested playing

17 calendar. Further research is nevertheless warranted to investigate the injury risk in

18 'star' players who may participate more frequently in consecutive matches within a tight

19 time frame over the course of the season.

Previous studies examining injuries in American Major League Soccer [22] and

21 the English Premier League [18] demonstrated no effect of four typical playing 22 positions (goalkeeper, defender, midfielder and forward) on the occurrence of injury.

23 The finding that centre-forwards in the present club incurred more injuries and sprains

24 in particular compared to other positional roles is therefore noteworthy. This result 25 suggest that future studies should analyse injury according to the precise positional role 
1 of the player as well as demonstrating a need for injury prevention training schemes to

2 be tailored to the individual positional role. However, care is needed when interpreting

3 these findings as injury rates and patterns were investigated according to the position

4 itself and on several occasions over the course of the season, players were rotated across

5 positions and may have found themselves in an unfamiliar positional role. Similarly,

6 some players may have changed playing positions during matches when substitutions or

7 changes in team formation were made. Further research is therefore required to discern

8 whether the position itself was the potential risk factor or whether certain individuals

9 across teams were simply more at risk of injury.

10 A limitation of the present study was that the cohort included players from only

11 one soccer club and the patterns observed may only be a reflection of this particular

12 team. Consequently, the findings may not be applicable to other elite soccer clubs.

13 Similar investigations involving a substantially larger sample of clubs to increase

14 statistical power and more injury cases to allow comparisons of variations in all injury

15 types and locations are therefore warranted. In addition, match exposure time and

16 injuries sustained in players with national team obligations and their links with the issue

17 of match congestion were not examined. A previous study showed that half of players

18 belonging to teams that participated in Champions League football were exposed to

19 international duties and $4 \%$ of all injuries occurred under these circumstances [25].

20 Furthermore, in order to suggest preventive strategies specific to soccer, it is necessary

21 to have detailed information combining game-specific and medical information on risk

22 factors for injury [1] and the mechanisms involved in match-play injuries [2] which

23 were not recorded in the present study. Nevertheless, the obvious strength of this

24 investigation is its long-term span and prospective nature. Also, the present study

25 methodology closely respects internationally recommended injury recording systems 
1 [9,12] specifically developed to address injury in soccer allowing the results to be

2 compared to current and future research into soccer injuries.

3

4 Conclusion

In professional soccer, continuous data over several seasons are needed to

6 observe the development of specific trends over time, but also to screen for areas of

7 concern and form injury prevention hypotheses. This study has shown that while the

8 risk and severity of injury has not changed over a four-year period and that the present

9 club coped well with a congested match calendar, patterns of injury can vary over time

10 and may depend on the types of fixture played or the precise positional role of the

11 player. Taken in total, the data from this study provide sports medicine practitioners

12 with useful information concerning the injury consequences of the game of soccer and

13 may aid medical and coaching staff in the care and management of playing resources. 
1 References

2 1.Arnason A, Sigurdsson SB, Gudmundsson A, Holme I, Engebretsen L, Bahr R. Risk

3 factors for injuries in football. Am J Sports Med 2004; 32(1 Suppl): 5S-16S.

4 2.Arnason A, Tenga A, Engebretsen L, Bahr R. A prospective video-based analysis of 5 injury situations in elite male football. Am J Sports Med 2004; 32: 1459-1465

6 3. Babwah, TJR. Incidence of Football Injury during International Tournaments. Res $7 \quad$ Sports Med 2009; 17: 61-69

8 4. Carling C, Orhant, E. Variation in body composition in professional soccer players:

9 inter- and intra-seasonal changes and the effects of exposure time and player 10 position. J Strength Cond Res (In press).

11 5. Di Salvo V, Gregson W, Atkinson G, Tordoff P, Drust B. Analysis of high intensity 12 activity in Premier League soccer. Int J Sports Med 2009; 30: 205-212.

13 6. Dvorak J, Junge A, Grimm K, Kirkendall D. Medical report from the 2006 FIFA 14 World Cup Germany. Br J Sports Med 2007; 41: 578-581

15 7. Ekstrand $\mathrm{J}$, Waldén $\mathrm{M}$, Hägglund $\mathrm{M}$, A congested football calendar and the 16 wellbeing of players: Correlation between match exposure of European footballers 17 before the World Cup 2002 and their injuries and performances during that World 18 Cup. Br J Sports Med 2004; 38: 493-497

19 8. Ekstrand J, Hägglund M, Waldén M. Injury incidence and injury patterns in 20 professional football-the UEFA injury study. $\mathrm{Br} \quad \mathrm{J}$ Sports Med 21 doi:10.1136/bjsm.2009.060582

22 9.Fuller CW, Ekstrand J, Junge A, et al. Consensus statement on injury definitions and 23 data collection procedures in studies of football (soccer) injuries. Br J Sports Med 2006; 40: 193-201 
1 10. Hägglund M, Waldén M, Ekstrand J. Injury incidence and distribution in elite

2 football-a prospective study of the Danish and the Swedish top divisions. Scand J

$3 \quad$ Med Sci Sports. 2005; 15: 21-28

4 11. Hägglund M, Waldén M, Ekstrand J. Injuries in Swedish elite football-a prospective 5 study on injury definitions, risk for injury and injury pattern during 2001. Scand J

$6 \quad$ Med Sci Sports 2005; 15: 118-125

7 12. Hägglund M, Walden M, Bahr R, Ekstrand J. Methods for epidemiological study of 8 injuries to professional football players: developing the UEFA model. Br J Sports $9 \quad$ Med 2005; 39:340-346

10 13. Hägglund M, Waldén $M$ and Ekstrand J. Previous injury as a risk factor for injury in 11 elite football: a prospective study over two consecutive seasons. Br J Sports Med $12 \quad 2006 ; 40: 767-772$

13 14. Hägglund M, Waldén M, Ekstrand J. UEFA injury study, an injury audit of 14 European Championships 2006 to 2008. Br J Sports Med 2009; 43: 483-489

15 15. Harriss DJ, Atkinson G. International Journal of Sports Medicine - Ethical 16 Standards in Sport and Exercise Science Research. Int J Sports Med 2009; 30: 701$17 \quad 702$.

16. Hawkins RD, Fuller CW. Risk assessment in professional football: an examination 19 of accidents and incidents in the 1994 World Cup finals. Br J Sports Med 1996;30:165-70.

21 17. Hawkins RD, Fuller CW. An examination of the frequency and severity of injuries 22 and incidents at three levels of professional football. Br. J. Sports Med. $1998 ; 32 ; 326-332$

24 18. Hawkins RD, Fuller CW. A prospective epidemiological study of injuries in four English professional football clubs. Br J Sports Med 1999; 33: 196-203 
1 19. Hawkins RD, Hulse MA, Wilkinson C, Hodson A, Gibson M. The association

2 football medical research programme: an audit of injuries in professional football.

$3 \quad$ Br J Sports Med 2001; 35: 43-47

4 20. Junge A, Dvorak J, Graf-Baumann T, Peterson L. Football injuries during FIFA tournaments and the Olympic Games, 1998-2001: development and implementation

6 of an injury-reporting system. Am J Sports Med 2004; 32(1 Suppl):80S-9S

7 21. Lago-Peñas, C. Consequences of a busy soccer match schedule on team 8 performance: Empirical evidence from Spain. International SportMed Journal 2009;

9 10: $86-94$

10 22. Morgan BE, Oberlander MA. An Examination of Injuries in Major League Soccer:

11 The Inaugural Season. Am J Sports Med 2001; 29: 426-430

12 23. Odetoyinbo K, Wooster B, Lane A. The effect of a succession of matches on the 13 activity profiles of professional soccer players. In: Science and Football VI. (ed 14 Reilly, T \& Korkusuz, F). Routledge, UK, 2007; 105-108

15 24. Parry L, Drust B. Is injury the major cause of elite soccer players being unavailable 16 to train and play during the competitive season? Phys Ther Sport 2006; 7: 58-64

17 25. Walden M, Hägglund $\mathrm{M}$, Ekstrand J, UEFA Champions League study: A 18 prospective study of injuries in professional football during the 2001-2002 season. $19 \quad$ Br J Sports Med 2005; 39: 542-546

20 26. Woods C, Hawkins R, Hulse M, Hodson A. The Football Association Medical 21 Research Programme: an audit of injuries in professional football-analysis of 22 preseason injuries. Br J Sports Med 2002; 36: 436-441 
Table 1 Incidence of match injury across playing seasons and match formats.

Incidences include $95 \%$ confidence intervals.

Means \pm standard deviations.

Table 2 Incidence of injury according to anatomic location and type across playing seasons. *p<0.05 compared to 2006/07 season.

Table 3 Incidence, layoff time per injury and common types of injury across positional roles. Incidences include $95 \%$ confidence intervals.

Means \pm standard deviations.

${ }^{*} \mathrm{p}<0.001$ compared to goalkeepers, $\mathrm{p}<0.01$ compared to central-defenders and wide-midfielders, $\mathrm{p}<0.05$ compared to fullbacks and central-midfielders.

$\# \mathrm{p}<0.001$ compared to all other positional roles.

Figure 1 Seasonal disposition of overall injury incidence and incidence of traumatic and overuse injuries 
Table 1 Incidence of match injury across playing seasons and match formats.

\begin{tabular}{|c|c|c|c|c|c|c|c|c|c|c|c|c|}
\hline \multirow[t]{2}{*}{ Season } & \multicolumn{3}{|c|}{ Total } & \multicolumn{3}{|c|}{ League } & \multicolumn{3}{|c|}{ Domestic Cup } & \multicolumn{3}{|c|}{ European Competition } \\
\hline & ames & Injuries & Incidence & Games & Injuries & Incidence & Games & Injuries & Incidence & Games & Injuries & Incidence \\
\hline 2005-2006 & 54 & 36 & $9.5(26.6-52.4)$ & 38 & 25 & $39.0(23.7-54.3)$ & 6 & 4 & $39.4(0.8-77.9)$ & 10 & 7 & $41.5(10.7-72.2)$ \\
\hline 2006-2007 & 53 & 28 & 31.2 & 38 & 23 & $35.8(13.6$ & 5 & $\mathbf{1}$ & $11.8(-11)$ & 10 & 4 & $23.7(0.5-46.9)$ \\
\hline 2007-2008 & 42 & 23 & 32.4 & 38 & 21 & $32.7(12.0$ & 4 & 2 & $29.6(-11$ & $x_{-1}$ & - & 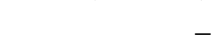 \\
\hline 2008-2009 & 43 & 43 & $59.0(17.6-76.6)$ & 38 & 36 & $55.9(24.2-47.8)$ & 5 & 7 & 82.6 & & & \\
\hline Mean per se & $.0 \pm 6.4$ & $32.5 \pm 8.8$ & $40.5(33.5-47.5)$ & $38 \pm 0.0$ & $26.3 \pm 6.7$ & $40.8(33.0-48.6)$ & $5.0 \pm 0.8$ & $3.5 \pm 2.6$ & $40.7(19.4-62.0)$ & $10 \pm 0.0$ & $5.5 \pm 2.1$ & $32.6(21.4-43.8)$ \\
\hline
\end{tabular}

Incidences include $95 \%$ confidence intervals.

Means \pm standard deviations 
Table 2 Incidence of injury according to anatomic location and type across playing seasons.

\begin{tabular}{|c|c|c|c|c|c|c|c|c|c|c|}
\hline \multirow[b]{3}{*}{ Injury location and type } & \multirow{2}{*}{\multicolumn{2}{|c|}{$2005 / 06$}} & \multirow{2}{*}{\multicolumn{2}{|c|}{$2006 / 07$}} & & & & & & \\
\hline & & & & & \multicolumn{2}{|r|}{$2007 / 08$} & \multicolumn{2}{|c|}{$2008 / 09$} & \multicolumn{2}{|c|}{ All seasons } \\
\hline & $\mathbf{N}$ & Incidence & $\mathbf{N}$ & Incidence & $\mathbf{N}$ & Incidence & $\mathbf{N}$ & Incidence & $\mathbf{N}$ & Incidence \\
\hline Knee & 12 & 13.2 & 4 & 4.5 & 4 & 5.6 & 8 & 11.0 & 28 & 8.6 \\
\hline Sprain & 4 & 4.4 & 1 & 1.1 & 2 & 2.8 & 1 & 1.4 & 8 & 2.5 \\
\hline Tendinopathy & 2 & 2.2 & 0 & 0.0 & 0 & 0.0 & 1 & 1.4 & 3 & 0.9 \\
\hline Chrondopathy & 0 & 0.0 & 2 & 2.2 & 1 & 1.4 & 2 & 2.7 & 5 & 1.5 \\
\hline Meniscus & 2 & 2.2 & 0 & 0.0 & 0 & 0.0 & 1 & 1.4 & 3 & 0.9 \\
\hline Contusion/haematoma & 4 & 4.4 & 1 & 1.1 & 1 & 1.4 & 3 & 4.1 & 9 & 2.8 \\
\hline Ankle & 6 & 6.6 & 4 & 4.5 & 5 & 7.0 & 11 & $15.1^{*}$ & 26 & 8.0 \\
\hline Sprain & 4 & 4.4 & 3 & 3.3 & 4 & 5.6 & 9 & 12.3 & 20 & 6.2 \\
\hline Tendinopathy & 0 & 0.0 & 0 & 0.0 & 1 & 1.4 & 0 & 0.0 & 1 & 0.3 \\
\hline Fracture & 1 & 1.1 & 0 & 0.0 & 0 & 0.0 & 1 & 1.4 & 2 & 0.6 \\
\hline Contusion/haematoma & 1 & 1.1 & 1 & 1.1 & 0 & 0.0 & 1 & 1.4 & 3 & 0.9 \\
\hline Lower leg & 1 & 1.1 & 6 & 6.7 & 2 & 2.8 & 4 & 5.5 & 13 & 4.0 \\
\hline Strain & 1 & 1.1 & 4 & 4.5 & 2 & 2.8 & 4 & 5.5 & 11 & 3.4 \\
\hline Tendinopathy & 0 & 0.0 & 1 & 1.1 & 0 & 0.0 & 0 & 0.0 & 1 & 0.3 \\
\hline Contusion/haematoma & 0 & 0.0 & 1 & 1.1 & 0 & 0.0 & 1 & 1.4 & 2 & 0.6 \\
\hline Groin & $\mathbf{1}$ & 1.1 & 2 & 2.2 & 1 & 1.4 & 8 & 11.0 & 12 & 3.7 \\
\hline Strain & 0 & 0.0 & 2 & 2.2 & 1 & 1.4 & 7 & 9.6 & 10 & 3.1 \\
\hline Tendinopathy & 1 & 1.1 & 0 & 0.0 & 0 & 0.0 & 1 & 1.4 & 2 & 0.6 \\
\hline Hamstring & 5 & 5.5 & 2 & 2.2 & 1 & 1.4 & 3 & 4.1 & 11 & 3.4 \\
\hline Strain & 3 & 3.3 & 2 & 2.2 & 1 & 1.4 & 3 & 4.1 & 9 & 2.8 \\
\hline Tendinopathy & 2 & 2.2 & 0 & 0.0 & 0 & 0.0 & 0 & 0.0 & 2 & 0.6 \\
\hline Quadriceps & 3 & 3.3 & 1 & 1.1 & 1 & 1.4 & 4 & 5.5 & 9 & 2.8 \\
\hline Strain & 1 & 1.1 & 1 & 1.1 & 1 & 1.4 & 3 & 4.1 & 6 & 1.8 \\
\hline Tendinopathy & 1 & 1.1 & 0 & 0.0 & 0 & 0.0 & 0 & 0.0 & 1 & 0.3 \\
\hline Contusion/haematoma & 1 & 1.1 & 0 & 0.0 & 0 & 0.0 & 1 & 1.4 & 2 & 0.6 \\
\hline Abdomen/thorax & 2 & 2.2 & 1 & 1.1 & 2 & 2.8 & $\mathbf{0}$ & 0.0 & 5 & 1.5 \\
\hline Strain & 1 & 1.1 & 1 & 1.1 & 1 & 1.4 & 0 & 0.0 & 3 & 0.9 \\
\hline Contusion/haematoma & 1 & 1.1 & 0 & 0.0 & 1 & 1.4 & 0 & 0.0 & 2 & 0.6 \\
\hline Foot & 1 & 1.1 & 1 & 1.1 & 2 & 2.8 & 2 & 2.7 & 6 & 1.8 \\
\hline Contusion/haematoma & 1 & 1.1 & 1 & 1.1 & 1 & 1.4 & 2 & 2.7 & 5 & 1.5 \\
\hline Other overuse & 0 & 0.0 & 0 & 0.0 & 1 & 1.4 & 0 & 0.0 & 1 & 0.3 \\
\hline Back/neck & 1 & 1.1 & 1 & 1.1 & 3 & 4.2 & $\mathbf{0}$ & 0.0 & 5 & 1.5 \\
\hline
\end{tabular}




$\begin{array}{lllllllllll}\text { Back/neck pain } & 1 & 1.1 & 1 & 1.1 & 2 & 2.8 & 0 & 0.0 & 4 & 1.2 \\ \text { Strain } & 0 & 0.0 & 0 & 0.0 & 1 & 1.4 & 0 & 0.0 & 1 & 0.3 \\ \text { Hand } & \mathbf{2} & \mathbf{2 . 2} & \mathbf{1} & \mathbf{1 . 1} & \mathbf{1} & \mathbf{1 . 4} & \mathbf{0} & \mathbf{0 . 0} & \mathbf{4} & \mathbf{1 . 2} \\ \quad \text { Fracture } & 2 & 2.2 & 1 & 1.1 & 1 & 1.4 & 0 & 0.0 & 4 & 1.2 \\ \text { Pelvis } & \mathbf{2} & \mathbf{2 . 2} & \mathbf{0} & \mathbf{0 . 0} & \mathbf{0} & \mathbf{0 . 0} & \mathbf{1} & \mathbf{1 . 4} & \mathbf{3} & \mathbf{0 . 9} \\ \quad \text { Strain } & 2 & 2.2 & 0 & 0.0 & 0 & 0.0 & 1 & 1.4 & 3 & \\ \text { Head/Face } & \mathbf{0} & \mathbf{0 . 0} & \mathbf{0} & \mathbf{0 . 0} & \mathbf{1} & \mathbf{1 . 4} & \mathbf{1} & \mathbf{1 . 4} & \mathbf{2} & \mathbf{0 . 6} \\ \quad \text { Fracture } & 0 & 0.0 & 0 & 0.0 & 0 & 0.0 & 1 & 1.4 & 1 & 0.3 \\ \text { Contusion/haematoma } & 0 & 0.0 & 0 & 0.0 & 1 & 1.4 & 0 & 0.0 & 1 & 0.3 \\ \text { Hip } & \mathbf{0} & \mathbf{0 . 0} & \mathbf{2} & \mathbf{2 . 2} & \mathbf{0} & \mathbf{0 . 0} & \mathbf{0} & \mathbf{0 . 0} & \mathbf{2} & \mathbf{0 . 6} \\ \text { Contusion/haematoma } & 0 & 0.0 & 2 & 2.2 & 0 & 0.0 & 0 & 0.0 & 2 & 0.6 \\ \text { Shoulder } & \mathbf{0} & \mathbf{0 . 0} & \mathbf{1} & \mathbf{1 . 1} & \mathbf{0} & \mathbf{0 . 0} & \mathbf{1} & \mathbf{1 . 4} & \mathbf{2} & \mathbf{0 . 6} \\ \quad \text { Sprain } & 0 & 0.0 & 1 & 1.1 & 0 & 0.0 & 1 & 1.4 & 2 & 0.6 \\ \text { Arm } & \mathbf{0} & \mathbf{0 . 0} & \mathbf{1} & \mathbf{1 . 1} & \mathbf{0} & \mathbf{0 . 0} & \mathbf{0} & \mathbf{0 . 0} & \mathbf{1} & \mathbf{0 . 3} \\ \quad \text { Fracture } & 0 & 0.0 & 1 & 1.1 & 0 & 0.0 & 0 & 0.0 & 1 & 0.3\end{array}$

$* \mathrm{p}<0.05$ compared to $2006 / 07$ season. 
1 Table 3 Incidence, layoff time per injury and common types of injury across positional roles.

\begin{tabular}{|c|c|c|c|c|c|c|}
\hline \multirow[t]{2}{*}{ Playing position } & \multicolumn{3}{|c|}{ Injuries } & \multicolumn{3}{|c|}{ Incidence } \\
\hline & Total & Incidence & $\begin{array}{r}\text { Layoff duration } \\
\text { (days) }\end{array}$ & Strains & Sprains & Contusions \\
\hline Goalkeepers & 7 & $23.8(6.2-41.4)$ & $16.1 \pm 11.8$ & $13.7(0.3-27.1)$ & 0.0 & $\mathbf{0 . 0}$ \\
\hline Fullbacks & 24 & $41.0(24.6-57.4)$ & $23.4 \pm 8.1$ & $12.0(3.1-20.9)$ & $10.2(2.0-18.4)$ & $12.0(3.1-20.9)$ \\
\hline Central-defenders & 21 & 35.7 (20.4-51.0) & $12.9 \pm 49.1$ & $6.8(0.1-13.5)$ & $13.7(4.2-23.2)$ & $10.3(2.1-18.5)$ \\
\hline Central midfielders & 30 & 36.3 (23.3 (49.3) & $11.5 \pm 19.8$ & $12.5(4.8-20.2)$ & $7.5(1.5-13.5)$ & $5.0(0.1-9.9)$ \\
\hline Wide-midfielders & 19 & $32.2(17.7-46.7)$ & $10.8 \pm 13.8$ & $12.0(3.1-20.9)$ & $6.8(0.1-13.5)$ & $10.2(2.0-18.4)$ \\
\hline Forwards & 29 & $77.2(49.1-105.3)^{*}$ & $18.6 \pm 29.2$ & $32.1(13.9-50.3)^{\#}$ & $13.4(1.6-25.1)$ & $8.0(-1.1-17.1)$ \\
\hline
\end{tabular}

Forward

$2977.2(49.1-105.3)$

$18.6+29.2-32.1(13.9-50.3)$

$13.4(1.6-25.1) \quad 8.0(-1.1-17.1)$

3 Incidences include 95\% confidence intervals.

4 Means \pm standard deviations.

$5 * \mathrm{p}<0.001$ compared to goalkeepers, $\mathrm{p}<0.01$ compared to central-defenders and wide-midfielders, $\mathrm{p}<0.05$ compared to fullbacks and central-midfielders

$6{ }^{\#} \mathrm{p}<0.001$ compared to all other positional roles. 
Figure 1 Seasonal disposition of overall injury incidence and incidence of traumatic and overuse injuries.

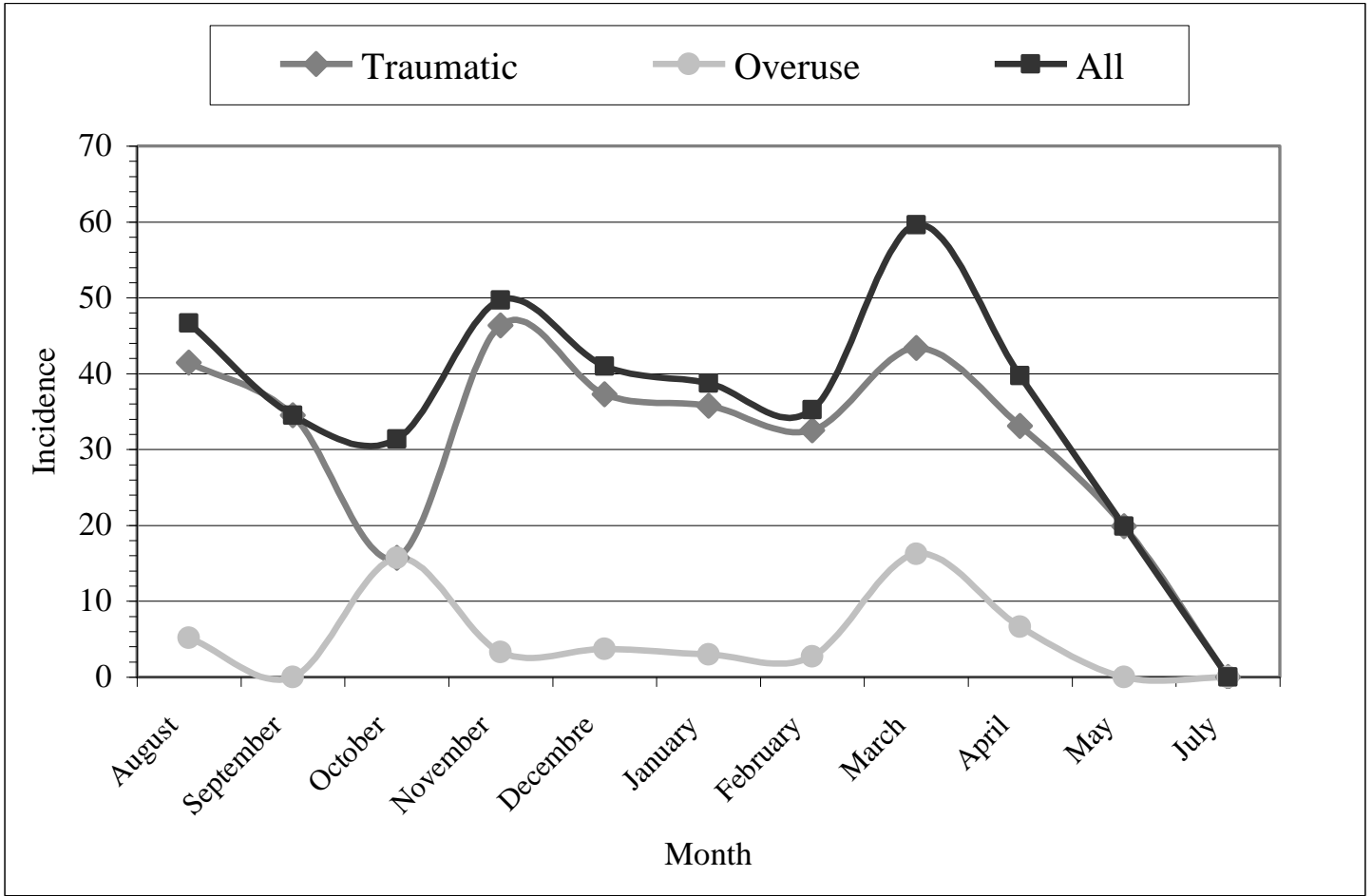

